\title{
The Leukocyte Common Antigen-Related Protein Tyrosine Phosphatase Receptor Regulates Regenerative Neurite Outgrowth In Vivo
}

\author{
Youmei Xie, Tracy T. Yeo, Cheng Zhang, Tao Yang, Michelle A. Tisi, Stephen M. Massa, and Frank M. Longo \\ Department of Neurology, University of California, San Francisco/Veteran's Administration Medical Center, San Francisco, \\ California 94121
}

\begin{abstract}
Drosophila and leech models of nervous system development demonstrate that protein tyrosine phosphatase (PTP) receptors regulate developmental neurite outgrowth. Whether PTP receptors regulate neurite outgrowth in adult systems or in regenerative states remains unknown. The leukocyte common antigenrelated (LAR) receptor is known to be present in rodent dorsal root ganglion (DRG) neurons; therefore, the well established model of postcrush sciatic nerve regeneration was used to test the hypothesis that LAR is required for neurite outgrowth in the adult mammalian nervous system. In uninjured sciatic nerves, no differences in nerve morphology and sensory function were detected between wild-type and LAR-deficient littermate transgenic mice. Sciatic nerve crush resulted in increased LAR protein expression in DRG neurons. In addition, nerve injury led to an increase in the proportion of LAR protein isoforms known to have increased binding affinity to neurite-promoting laminin-
\end{abstract}

nidogen complexes. Two weeks after nerve crush, morphological analysis of distal nerve segments in LAR-deficient transgenic mice demonstrated significantly decreased densities of myelinated fibers, decreased axonal areas, and increased myelin/axon area ratios compared with littermate controls. Electron microscopy analysis revealed a significant twofold reduction in the density of regenerating unmyelinated fibers in LAR $-/-$ nerves distal to the crush site. Sensory testing at the 2 week time point revealed a corresponding $3 \mathrm{~mm}$ lag in the proximal-to-distal progression of functioning sensory fibers along the distal nerve segment. These studies introduce PTP receptors as a major new gene family regulating regenerative neurite outgrowth in vivo in the adult mammalian system.

Key words: LAR; protein tyrosine phosphatase receptor; PTP; nerve regeneration; sciatic nerve; dorsal root ganglion; neurite outgrowth
Evidence that protein tyrosine phosphatase (PTP) receptors regulate neurite outgrowth in vivo has been derived primarily from insect models (for review, see Desai et al., 1997; Stoker and Dutta, 1998; Van Vactor, 1998; Chisholm and Tessier-Lavigne, 1999; den Hertog, 1999; Bixby, 2000). Studies of Drosophila mutants show that the Drosophila leukocyte common antigen-related (Dlar) PTP receptor modulates neurite pathfinding during development (Krueger et al., 1996; Sun et al., 2000). Null-mutant crosses suggest that Dlar influences signal transduction of Robo, DCC, cadherin, and other neurite-modulating receptors and that the phosphorylation of Ena, a regulator of growth cone actin polymerization, is controlled by opposing actions of Dlar and the Abl tyrosine kinase (Wills et al., 1999a,b; Bashaw et al., 2000; Lanier and Gertler, 2000). Drosophila studies also demonstrate that Dlar and Abl interact with Trio, a regulator of the Rac and Rho GTP-binding proteins that in turn control actin assembly and neurite outgrowth (Bateman et al., 2000; Liebl et al., 2000; Lin and Greenberg, 2000). Inhibition of HmLAR2, the leech ortholog of Dlar, leads to neurite navigational errors and growth

Received Jan. 8, 2001; revised April 17, 2001; accepted May 1, 2001

This work was supported by the Muscular Dystrophy Association, a Paul Beeson Award from the American Federation for Aging Research, National Institute on Aging Grant R01 AG09873, and the Veteran's Administration.

Correspondence should be addressed to Dr. Frank M. Longo, Department of Neurology, V-127, Veteran's Administration Medical Center/University of California, San Francisco, 4150 Clement Street, San Francisco, CA 94121. E-mail: lfm@itsa.ucsf.edu.

C. Zhang's present address: Department of Neurology, Sun Yat-Sen University of Medical Sciences, Guangzhou 510080, China.

Copyright $\odot 2001$ Society for Neuroscience $0270-6474 / 01 / 215130-09 \$ 15.00 / 0$ cone collapse (Gershon et al., 1998; Baker and Macagno, 2000; Baker et al., 2000).

Less is known regarding PTP receptor function during neurite outgrowth in mammalian systems. Leukocyte common antigenrelated (LAR) mRNA is expressed in neurons (Longo et al., 1993; Schaapveld et al., 1998), LAR protein is present along neurites and in growth cones (Honkaniemi et al., 1998; Zhang et al., 1998), and LAR alternative splicing is coordinated in a spatiotemporal manner during development (Zhang and Longo, 1995). Links between mammalian LAR and regulation of the actin cytoskeleton are suggested by the findings that LAR binds to Trio in mammalian cells and that Mena, the mammalian ortholog of Ena, is concentrated at the tips of growth cones (Debant et al., 1996; Lanier et al., 1999). Studies in two different models of transgenic LAR-deficient mice reveal decreased cholinergic fiber innervation of the dentate gyrus (Yeo et al., 1997; Van Lieshout et al., 2000). The ligand(s) regulating LAR remain unknown, although certain LAR isoforms bind to laminin-nidogen complexes (O'Grady et al., 1998). Function of other LARtype PTP receptors during mammalian neural development is suggested by the findings of neuroendocrine dysplasia in PTP $\sigma$ mutant mice (Elchebly et al., 1999; Wallace et al., 1999) and altered learning and long-term potentiation in PTP $\delta$ mutants (Uetani et al., 2000). The findings that PTP $\sigma$ and PTP $\delta$ promote neurite outgrowth in vitro (Ledig et al., 1999; Wang and Bixby; 1999) will encourage studies determining whether they also regulate neurite outgrowth in vivo.

Although Drosophila and murine mutant studies demonstrate that certain PTP receptors regulate neurite outgrowth during 
A

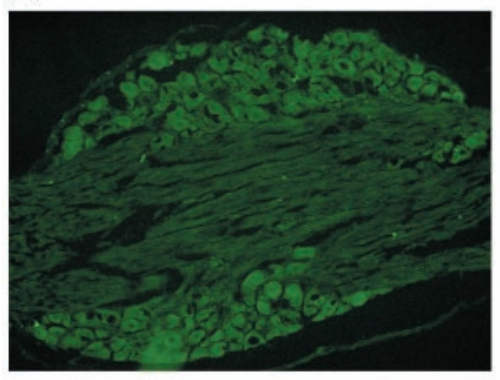

C

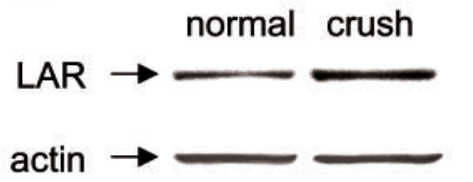

E

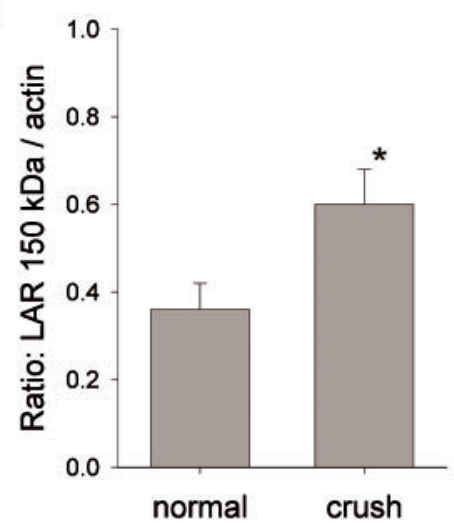

B

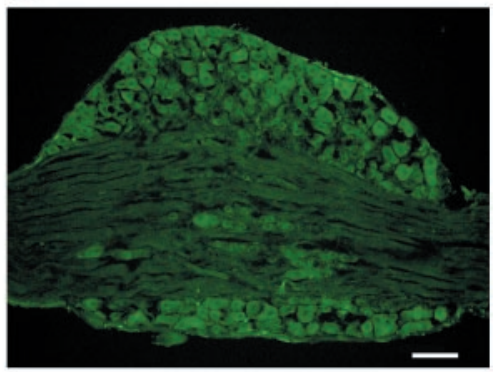

D

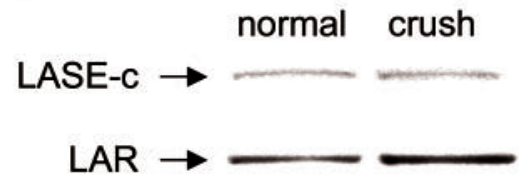

$\mathrm{F}$

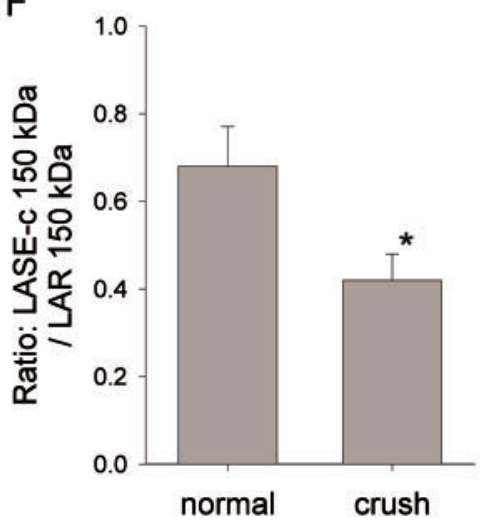

Figure 1. LAR protein in DRG after nerve crush. DRG frozen sections obtained from uninjured mice $(A)$ and 2 weeks after nerve crush $(B)$ were immunostained using monoclonal antibody directed against the $\mathrm{N}$ terminal of LAR $\sim 150 \mathrm{kDa}$ ectodomain. Staining patterns from both uninjured and postcrush tissue appear similar and are consistent with previous localizations of LAR to neurons and neural processes. Scale bar, $0.1 \mathrm{~mm}$. $C-F$, Protein extracts were prepared from lumbar DRG (L4-L6) pooled from eight normal uninjured mice and from eight mice 2 weeks after bilateral nerve crush. Western blot analysis of DRG extracts was performed using the same LAR N-terminal antibody used for tissue immunostaining. Blots were reprobed using antibody directed against the LASE-c insert present in the LAR $\sim 150 \mathrm{kDa}$ extracellular domain, followed by antibody to $\beta$-actin to control for protein loading. $E$, The ratio of LAR to $\beta$-actin signal increased by $66 \%$ $\left(n=6\right.$; Western analyses; mean $\pm \mathrm{SE}$; ${ }^{*} p<0.05$; MannWhitney rank sum test). $F$, In the same samples, the ratio of LASE-c to LAR signal decreased by $38 \%(n=6$; Western analyses; mean $\pm \mathrm{SE}$; ${ }^{*} p<0.05$; Mann-Whitney rank sum test). development, it remains unknown whether PTP receptors modulate plasticity or regenerative neurite outgrowth in the adult state. The present study addresses the hypothesis that LAR regulates neurite outgrowth in the adult in vivo by assessing LAR expression after nerve injury and by comparing nerve morphology and sensory function in uninjured and in regenerating nerves in $\mathrm{LAR}+/+$ and $\mathrm{LAR}-/$ - transgenic littermate mice.

\section{MATERIALS AND METHODS}

Experimental animals. LAR-transgenic mice containing a $\beta$-galactosidase/neomycin ( $\beta$-geo) reporter transgene in the intron between exons 6 and 7 of the LAR gene were obtained from Dr. William Skarnes (Department of Molecular and Cell Biology, University of California, Berkeley, Berkeley, CA) (LAR transgenic line \#534; Skarnes et al., 1995). The transgene also contains an En-2 splice acceptor that functions as a "gene trap," resulting in the expression of a fusion protein containing a small segment of the LAR extracellular $\mathrm{N}$ terminal (the first two Ig-like domains) with the remainder of the receptor replaced by the $\beta$-geo protein. The LAR/ $\beta$-geo fusion protein omits $>90 \%$ of the LAR receptor, including the bulk of the extracellular region (the third Ig-like domain along with the eight FNIII domains) and the entire intracellular region (phosphatase domains). Northern analysis of mRNA derived from mice homozygous for the $\beta$-geo transgene (LAR-/-) demonstrate only trace levels of full-length LAR transcripts (Skarnes et al., 1995; Yeo et al., 1997). The original colony created in the laboratory of Dr. Skarnes was founded in a 129/Ola/DBA strain background and maintained via successive DBA backcrosses. On arrival in our laboratory, these mice were bred over a 3 year period by continuing backcrosses with wild-type DBA. Mice used in the present study were derived via a minimum of six
DBA backcrosses. Genotyping was conducted using reverse transcription-PCR as described previously (Yeo et al., 1997). LAR+/littermate crosses were used to generate $\mathrm{LAR}+/+$ and $\mathrm{LAR}-/-$ littermates. All studies were limited to littermate comparisons, and mice were studied at 3-5 months of age.

Sciatic nerve crush. Sciatic nerves of anesthetized mice were exposed bilaterally through a gluteal muscle incision. Nerve compression was performed $2 \mathrm{~mm}$ distal to the sciatic notch by placing a stainless steel rod parallel to the nerve, looping a $6-0$ silk suture around both the rod and the nerve, and pulling the suture firmly for $20 \mathrm{sec}$. The injured area was marked with a single epineural suture (11-0 silk).

$D R G$ immunostaining. Mice were anesthetized and perfused through the left cardiac ventricle with heparinized PBS, followed by $100 \mathrm{ml}$ of $4 \%$ paraformaldehyde in PBS, $\mathrm{pH}$ 7.4. Lumbar dorsal root ganglia (DRG) were removed and immersion fixed for $3 \mathrm{hr}$ at $4^{\circ} \mathrm{C}$ in the same fixative solution. Tissue was cryoprotected with $20 \%$ sucrose in PBS at $4^{\circ} \mathrm{C}$ overnight and frozen in methylbutane at $-30^{\circ} \mathrm{C}$. Fourteen-micrometerthick sections were cut with a cryostat and mounted onto Superfrost slides. Sections were incubated with blocking solution (5\% goat serum, $3 \%$ BSA, and $0.1 \%$ Tween 20 in PBS) for $2 \mathrm{hr}$ at room temperature, followed by overnight incubation with previously characterized (Yang et al., 2000) LAR monoclonal antibody (Transduction Laboratories, Lexington, KY) diluted $1: 1000$ in $0.1 \%$ BSA and $0.1 \%$ Tween 20 in PBS. After incubation, sections were washed three times with PBS and then incubated with Alexa Fluor 488 goat anti-mouse IgG (Molecular Probes, Eugene, OR) diluted 1:500 in 0.1\% BSA and 0.1\% Tween 20 in PBS. Sections were washed three times with PBS, treated with Prolong Antifade (Molecular Probes), coverslipped, and photographed using a Zeiss (Thornwood, NY) Axioplan 2 microscope.

Western blot analysis. Tissues were lysed in lysis buffer (20 mM Tris- 
$\mathrm{HCl}, \mathrm{pH}$ 7.5, $137 \mathrm{~mm} \mathrm{NaCl}, 1 \%$ Nonidet P-40, 10\% glycerol, $500 \mu \mathrm{M}$ sodium orthovanadate, $1 \mathrm{~mm}$ phenylmethylsulfonyl fluoride, $10 \mu \mathrm{g} / \mathrm{ml}$ aprotinin, and $1 \mu \mathrm{g} / \mathrm{ml}$ leupeptin) for $30 \mathrm{~min}$. Aliquots containing $10 \mu \mathrm{g}$ of protein were run on $6 \%$ SDS polyacrylamide gels with a $5 \%$ stacking gel, followed by transfer to polyvinylidene difluoride membranes (Amersham Pharmacia Biotech, Arlington Heights, IL). Membranes were incubated in 5\% nonfat dry milk (Bio-Rad, Hercules, CA) in TBST (20 $\mathrm{mm}$ Tris-HCl, pH 7.5, $137 \mathrm{~mm}$, and $0.2 \%$ Tween 20) for $1 \mathrm{hr}$ at room temperature and then incubated overnight with primary antibody. For detection of LAR, primary antibody consisted of the same monoclonal antibody directed against the $\mathrm{N}$ terminus of LAR $(0.5 \mu \mathrm{g} / \mathrm{ml})$ used above for immunostaining. LAR isoforms containing the nine residue LAR alternatively spliced element-c (LASE-c) insert were detected using previously characterized rabbit polyclonal antibody raised against LASE-c (1 $\mu \mathrm{g} / \mathrm{ml})$ (Zhang et al., 1998). $\beta$-Actin was detected using monoclonal antibody purchased from Sigma (St. Louis, MO). For monoclonal primary antibodies, secondary antibody consisted of peroxidaseconjugated goat anti-mouse $\operatorname{IgG}$ (1:20,000 dilution; Dako, Carpinteria, CA). For the polyclonal primary antibody, secondary antibody consisted of peroxidase-conjugated goat anti-rabbit IgG (1:20,000 dilution; Pierce, Rockford, IL). Membranes were processed for chemiluminescence detection using the Amersham ECL detection kit and exposed to x-ray film for $0.5-5 \mathrm{~min}$ to obtain a range of exposures. Autoradiographs in the linear range were densitometrically scanned.

Light microscopy morphological analysis. Morphological analysis was conducted using protocols similar to those described by Rath et al. (1995). Mice were anesthetized and perfused through the left cardiac ventricle with an ice-cold solution of $4 \%$ paraformaldehyde and $2.5 \%$ glutaraldehyde in $0.1 \mathrm{M}$ phosphate buffer, $\mathrm{pH}$ 7.4. Nerves were removed with orientation maintained and immersion fixed overnight at $4{ }^{\circ} \mathrm{C}$ in the same fixative solution. Tissues were rinsed three times in $0.05 \mathrm{M}$ sodium phosphate buffer, $\mathrm{pH} 7.4$, and post-fixed in Dalton's osmium solution (4\% $\mathrm{K} 2 \mathrm{Cr} 2 \mathrm{O} 7, \mathrm{pH} 7.35,3.4 \% \mathrm{NaCl}$, and $4 \% \mathrm{OsO} 4$ in a 1:1:2 ratio) for $2 \mathrm{hr}$.
Tissues were then alcohol dehydrated, propylene oxide treated, and infiltrated and subsequently embedded in Spurr's resin (Polysciences, Warrington, PA). One-micrometer-thick semithin cross-sections were cut and stained with paraphenylenediamine. Digital images were captured at a magnification of $400 \times$ using a Nikon (Tokyo, Japan) Labophot microscope and the microcomputer imaging device Imaging Research Inc. (St. Catharines, Canada) program. From each cross-section image, two to four fields, each covering $\sim 10^{4} \mu \mathrm{m}^{2}$, were randomly selected for image analysis. For each field, the circumference of each myelinated axon and each myelin profile was manually outlined using procedures similar to those described by Auer (1994). In each section, the average number of myelinated fibers per field was determined, and the resulting average number of myelinated fibers per square micrometer was calculated. Nerve fiber and myelin areas were calculated using NIH Image and displayed using a histogram format. All morphometry studies were conducted in a blinded manner using coded sections.

Electron microscopy morphological analysis. Thin sections were mounted on 300-mesh nickel grids, stained with lead citrate and uranyl acetate, and photographed with a Philips 10 Bioscan electron microscope operating at $80 \mathrm{kV}$. For each cross-section, 15 randomly selected electron micrograph fields (encompassing $6-7 \%$ of total nerve crosssectional area) of tissue area not covered by grid bars were photographed. Micrographs, each covering an area of $850 \mu \mathrm{m}^{2}$, were examined at a final magnification of $7280 \times$, and the number of unmyelinated axonal profiles was counted without knowledge of genotype. Profiles of unmyelinated fibers were readily distinguished from Schwann cell profiles using criteria (Jenq and Coggeshall, 1984; Gibbels, 1989) widely applied to nerve regeneration studies (Longo et al., 1986). Characteristic unmyelinated fibers have relatively low electron density, contain abundant microtubule profiles, and are surrounded by a relatively electron-dense axolemma.

Temperature sensitivity assay (hot plate test). Temperature sensitivity was tested in a blinded manner using the hot plate test (Kanaan et al., a.

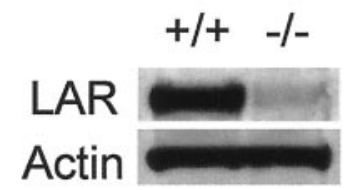

c.

Figure 2. Uninjured sciatic nerve morphology and function in $\mathrm{LAR}+/+$ versus $\mathrm{LAR}-/-$ mice. $a$, Protein extracts were prepared from lumbar DRG (L4L6) pooled from four $\mathrm{LAR}+/+$ and four $\mathrm{LAR}-/-$ uninjured mice. Western blot analysis of DRG extracts was performed using monoclonal antibody directed against the $\mathrm{N}$ terminal of the $\mathrm{LAR} \sim 150 \mathrm{kDa}$ ectodomain. Blots were reprobed using antibody directed against $\beta$-actin to control for protein loading. Only trace levels of LAR protein were detected in DRG tissue derived from LAR $-/-$ mice. $b$, Visual examination of $1-\mu \mathrm{m}$-thick semithin cross-sections of uninjured sciatic nerve stained with paraphenylenediamine revealed no apparent differences in nerve structure between $\mathrm{LAR}+/+$ and $\mathrm{LAR}-/-$ mice. Scale bar, $10 \mu \mathrm{m} . c-e$, Quantitative morphological analysis performed on nerves derived from three mice of each genotype showed no detectable differences in myelinated fiber density or in axonal and myelin areas. Mean \pm SE. $f$, Analysis of axonal areas demonstrated no significant difference in size distributions between $\mathrm{LAR}+/+$ and $\mathrm{LAR}-/-$ nerves ( $p=0.214$; Kolmogorov-Smirnov test). $g$, Pain threshold testing using the hot plate test revealed no detectable differences in temperature reaction latency between $\mathrm{LAR}+/+(n=11$ mice $)$ and LAR $-/-(n=8$ mice $)$ mice. Mean \pm SE.

b.

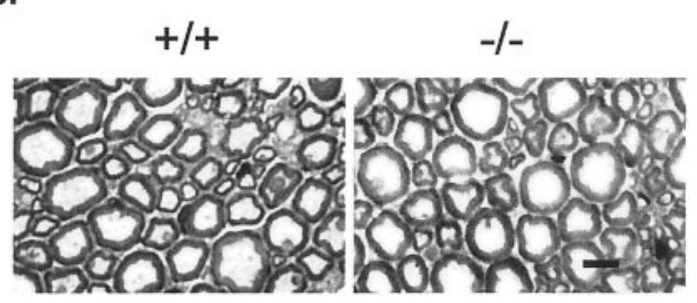

d.

e.

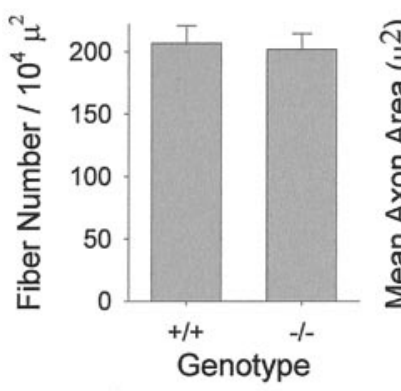

f.

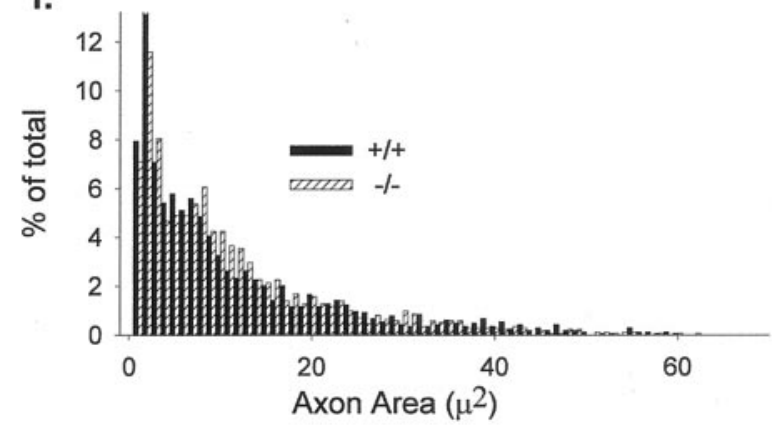

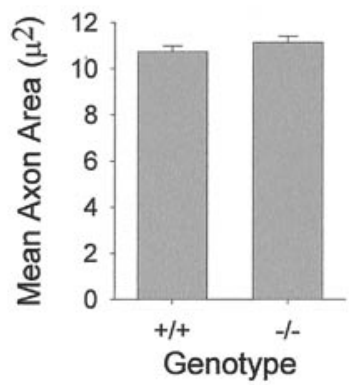

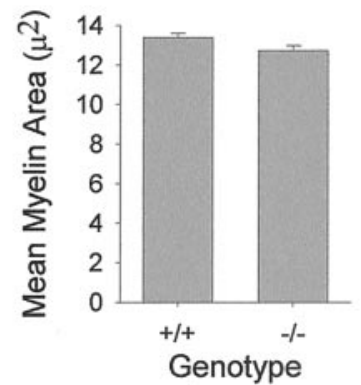

g.

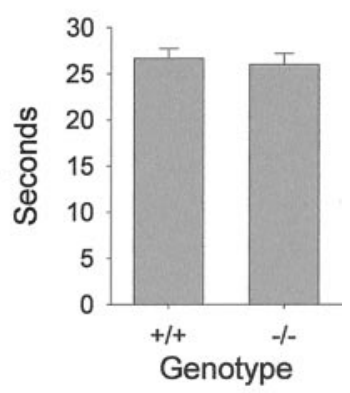



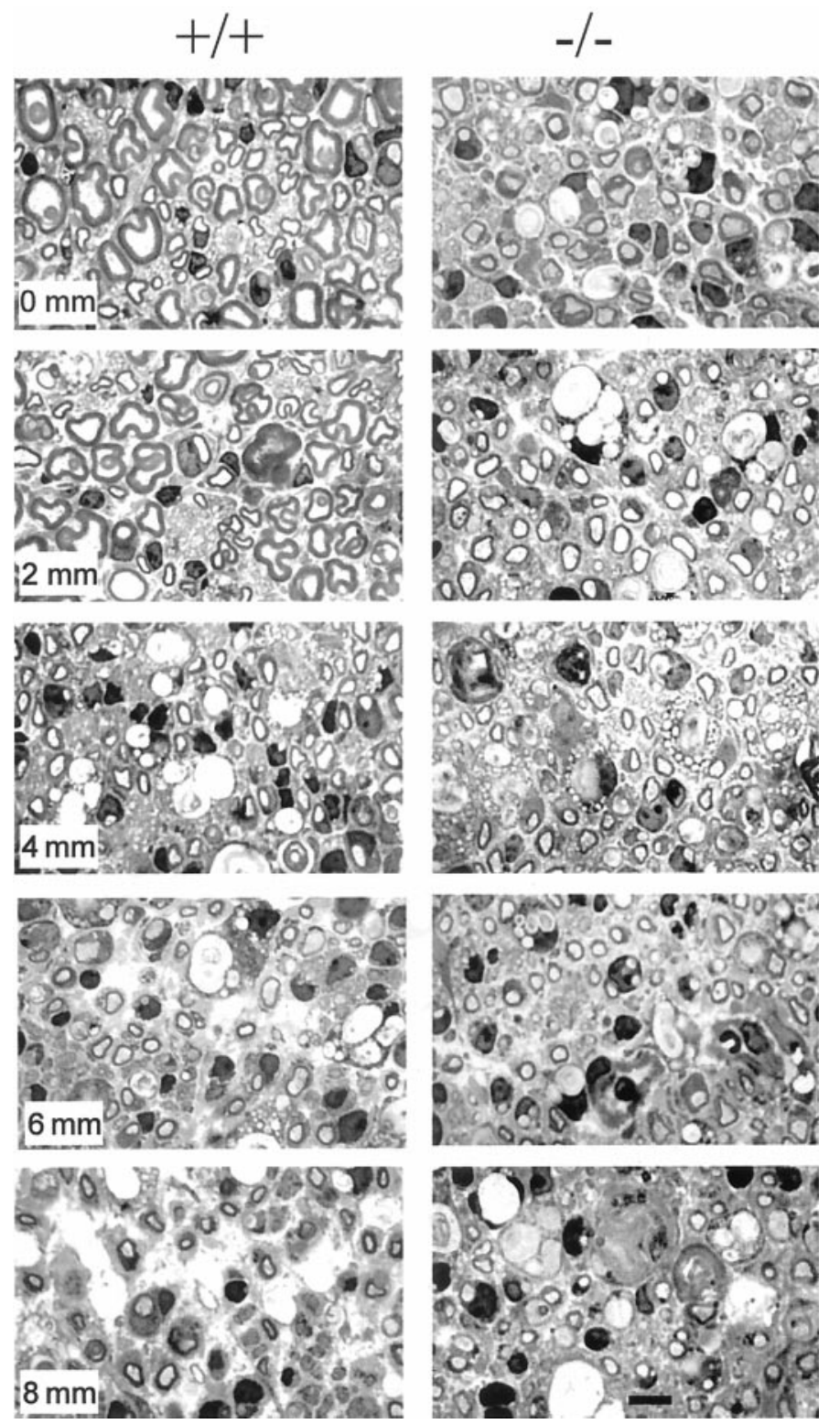

Figure 3. Gross morphology of sciatic nerve 2 weeks after crush. Two weeks after sciatic nerve crush, $1-\mu \mathrm{m}$-thick semithin paraphenylenediamine-stained cross-sections obtained from $\mathrm{LAR}+/+$ and LAR $-/-$ mice at the crush site $(0 \mathrm{~mm})$ and at $2 \mathrm{~mm}$ increments distal to the crush site were examined. Gross inspection suggested decreased density of myelinated fibers in LAR $-/-$ sections at the 2 and $4 \mathrm{~mm}$ points. In proximal $\mathrm{LAR}-/-$ sections $(0$ and $2 \mathrm{~mm})$, axonal areas and myelin areas also appeared to be reduced. Scale bar, $10 \mu \mathrm{m}$.

1996). Sensitivity to heat was assessed by placing mice on the surface of an aluminum hot plate set to $50^{\circ} \mathrm{C}$. The duration until the mice first lifted their forepaws or hindpaws was recorded.

Sensory nerve regeneration pinch test. The sensory pinch test was used to evaluate regeneration of functioning sensory fibers (James et al., 1993). After anesthesia and reexposure, the sciatic nerve was pinched with microforceps at increments of $1 \mathrm{~mm}$ starting distally and moving proximally until a clear motor reflex response of the proximal hindleg or paraspinal muscle (nonsciatic nerve dependent) was obtained. At that point, the distance in millimeters between the crush site and the stimulus site was measured using a $0.1 \mathrm{~mm}$ scale under a dissecting microscope. Independent measurements by two individuals, blinded to genotype, were averaged to yield one determination per nerve.

\section{RESULTS}

\section{DRG neuronal LAR expression after nerve crush}

Previous in situ and immunostaining studies demonstrated that LAR is primarily expressed by DRG neurons with low or absent expression associated with non-neurons (Longo et al., 1993; Haworth et al., 1998; Honkaniemi et al., 1998; Zhang et al., 1998). To determine whether LAR protein continues to be expressed by DRG neurons after nerve crush, DRG isolated from uninjured animals and 2 weeks after lesion were processed for LAR immunostaining. Immunostaining was conducted using a previously characterized monoclonal antibody directed against the $\mathrm{N}$ terminus of the LAR $\sim 150 \mathrm{kDa}$ extracellular subunit. The pattern of DRG LAR protein expression 2 weeks after injury appeared similar to that found in uninjured mice (Fig. $1 A, B$ ). LAR was expressed by most neurons, and signal was also evident along fibers emanating from the DRG. Consistent with Western blot analyses of LAR - /- DRG described below, immunostaining of DRG sections obtained from LAR $-/-$ mice resulted in the absence of signal (data not shown). LAR protein expression in DRG isolated from uninjured animals and 2 weeks after lesion was also examined via Western blot analysis using the same LAR antibody used for immunostaining. After nerve crush, LAR protein levels were increased by $\sim 1.7$-fold (Fig. $1 C, E$ ). In contrast, Western blot analysis using antibody directed against the LASE-c insert present in the LAR extracellular domain demonstrated an $\sim 40 \%$ decrease in the proportion of LAR protein isoforms containing LASE-c (Fig. 1D,F).

\section{Sciatic nerve morphology and function in uninjured LAR-deficient mice}

Transgenic mice containing the $\beta$-geo transgene in the $5^{\prime}$ end of the LAR gene were shown previously to have markedly decreased levels of full-length LAR transcripts (Skarnes et al., 1995; Yeo et al., 1997). These mRNA studies predicted that LAR protein levels would demonstrate a corresponding decrease. In the present study, Western blot analysis using LAR N-terminal antibody was used to compare LAR protein levels in DRG of $\mathrm{LAR}+/+$ and $\mathrm{LAR}-/-$ littermates. In LAR $+/+$ DRG, LAR protein was readily detected, whereas in LAR-/- DRG, only trace levels of the LAR $\sim 150 \mathrm{kDa}$ protein were detected (Fig. $2 a$ ). Confirmation of decreased LAR protein levels confirmed that these $\beta$-geo gene-trap mice could serve as a model for assessment of nerve morphology and function in the LARdeficient state. In uninjured nerves, morphological analyses, including overall appearance, fiber density, axonal area and myelin area, detected no differences in phenotype between $\mathrm{LAR}+/+$ and LAR $-/-$ littermate mice (Fig. $2 b-e$ ). Analysis of axonal area distributions detected no significant differences between the LAR $+/+$ and LAR $-/-$ nerves (Fig. $2 f$ ). Functional analysis of pain withdrawal responses found no detectable differences in hot plate reaction times (Fig. $2 g$ ). In addition, LAR-/- mice were not found to have skin lesions, signs of self-mutilation, or other indicators of sensory loss. Thus, morphological and functional observations found no overt evidence of developmental anomalies or neuropathy in LAR-deficient mice.

\section{Impaired sciatic nerve regeneration in LAR-deficient mice}

Postcrush regenerative neurite outgrowth was assessed using the well established morphometric approaches of measuring density, axonal area, and myelin area of myelinated nerve fibers (Frykman et al., 1988; Griffin and Hoffman, 1993; Auer, 1994; Rath et al., 
Figure 4. Sciatic nerve fiber density, axonal area, and myelin area analyses 2 weeks after crush. Two weeks after nerve crush, crosssections were obtained from LAR $+/+$ (open circles) and LAR $-1-$ ( filled circles) nerves at points $2 \mathrm{~mm}$ proximal to the crush site $(-2$ $\mathrm{mm})$, at the crush site $(0 \mathrm{~mm})$, and at $2 \mathrm{~mm}$ increments distal to the crush site. Six nerves of each genotype were examined. The number of myelinated fibers per area, axonal areas, and myelin areas were measured in two to four randomly selected fields per section. $A$, The mean number of myelinated fibers per field was calculated and expressed as the number of fibers per $10^{4} \mu \mathrm{m}^{2}$. The mean fiber density derived from a given nerve segment and genotype was calculated. Mean $\pm \mathrm{SE}$ are shown. At the 2 and $4 \mathrm{~mm}$ points, significant decreases in fiber density in $\mathrm{LAR}-/$ - compared with $\mathrm{LAR}+/+$ sections were found (Mann-Whitney rank sum test). In addition, in $\mathrm{LAR}+/+$ nerves, fiber density at the $2 \mathrm{~mm}$ point was increased significantly compared with that at the crush site $(p=0.008)$ and the $-2 \mathrm{~mm}$ proximal site $(p=$ 0.049). $B$, Axonal areas in sections from LAR $-/-$ mice were significantly reduced at the crush site and in all distal sections. Reductions were particularly large at the crush site and at the $2 \mathrm{~mm}$ site ( ${ }^{*} p<0.001$; MannWhitney rank sum test). $C$, Myelin areas in

LAR $-/-$ mice were significantly increased at the $-2 \mathrm{~mm}$ proximal site and significantly decreased at the crush site and all distal sites. This decrease was particularly evident at the crush site and at the $2 \mathrm{~mm}$ site $\left({ }^{*} p<0.001\right.$; Mann-Whitney rank sum test). $D$, In all sections except the $8 \mathrm{~mm}$ distal point, myelin/axon area ratios were increased in $\mathrm{LAR}-1-$ mice $\left({ }^{*} p<0.001\right.$; Mann-Whitney rank sum test).
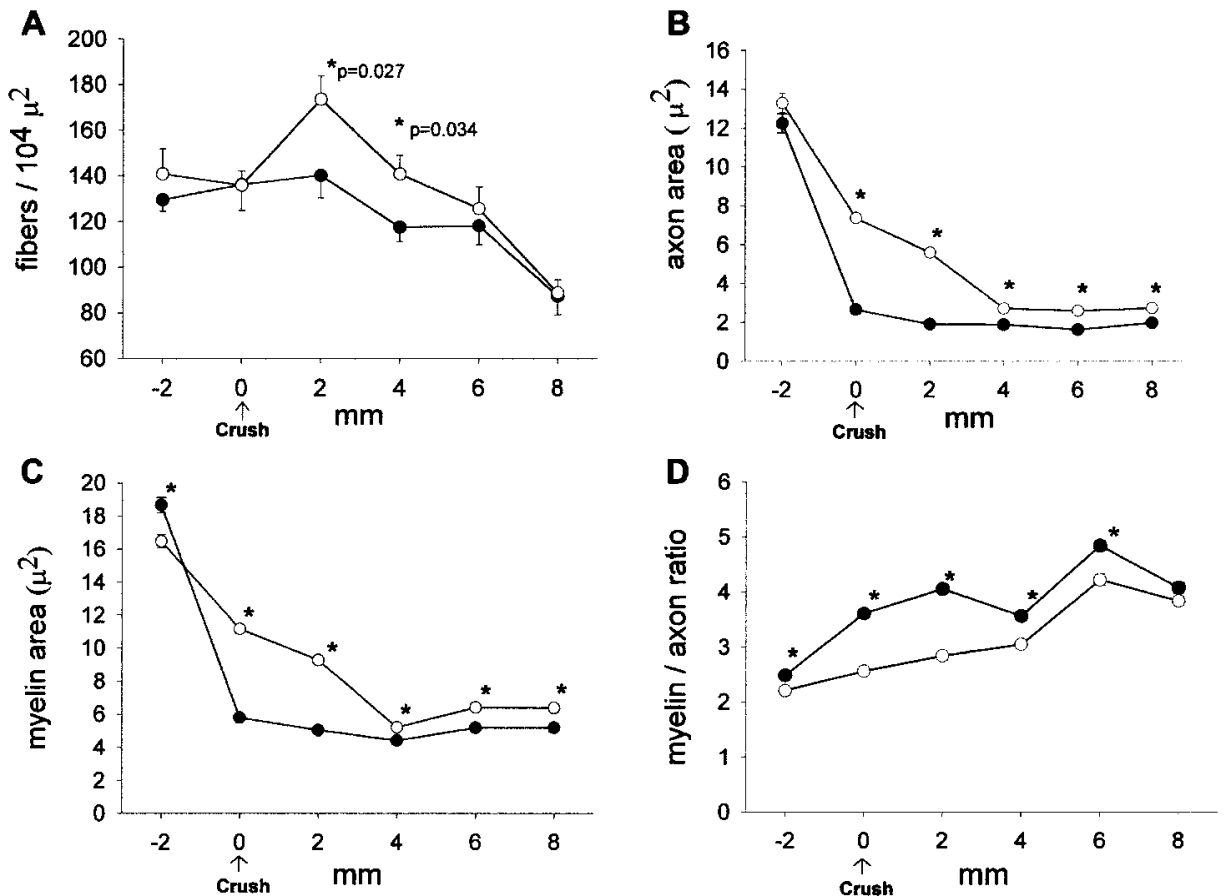

1995). Other important methods of assessing regenerative fiber outgrowth include immunostaining with antibodies directed against various cytoskeletal-associated proteins or monitoring the profile of axonally transported proteins or markers (Frykman et al., 1988). However, in transgenic models, the expression of specific marker proteins and/or rates of axonal transport might potentially be affected by the absence of the gene of interest independently of actual alterations in regenerative fiber outgrowth. Thus, the present study applied standard morphometric measures of nerve regeneration that are not dependent on expression levels or axonal transport profiles of specific marker proteins.

Preliminary studies in LAR $+/+$ mice indicated that postcrush regenerative fiber outgrowth reached a point just distal to the midthigh level at the 2 week time point. To examine morphological profiles over an optimal distance proximal and distal to the crush site and to most accurately compare regenerative profiles between the normal and the potentially impaired state at a given time point, the 2 week time point was chosen for in depth analyses. Visual inspection of transverse sections harvested 2 weeks after nerve crush suggested a decrease in the density of myelinated fibers and decreases in axonal area and myelin area in $\mathrm{LAR}-/$ - compared with $\mathrm{LAR}+/+$ nerves at the $2 \mathrm{~mm}$ and $4 \mathrm{~mm}$ points distal to the crush site (Fig. 3).

Quantitation of total nerve trunk cross-sectional areas did not detect a significant difference in nerve cross-sectional area between $\mathrm{LAR}+/+$ and $\mathrm{LAR}-/$ - nerves in either proximal or distal segments (data not shown). However, consistent with visual inspection, quantitative analysis of individual fibers demonstrated significant decreases in myelinated fiber density in LAR-/nerves compared with $\mathrm{LAR}+/+$ nerves at the 2 and $4 \mathrm{~mm}$ points distal to the crush site (Fig. $4 A$ ). This decrease in myelinated fiber density suggested a loss of formation of myelinated fibers and possibly a loss of fiber outgrowth in LAR - / - nerves. Quantitative analysis also showed significant decreases of axonal area and myelin area at the crush point and in all distal sections (Fig. $4 B, C)$. Interestingly, in $\mathrm{LAR}-/-$ nerves, the ratios of myelin area over axonal area were significantly increased (Fig. 4D). The disproportionate loss of axonal versus myelin areas in LAR-/nerves suggested a primarily axonal rather than myelin deficiency. For each of the parameters of fiber density, axonal area, and myelin area, there was an $\sim 2-4 \mathrm{~mm}$ proximal-to-distal lag in $\mathrm{LAR}-/-$ values compared with $\mathrm{LAR}+/+$ values (Fig. 4A-C). Size distribution analyses of axonal areas demonstrated significant decreases in the proportions of fibers with larger areas at the $0 \mathrm{~mm}$ crush site and at the $2 \mathrm{~mm}$ distal site (Fig. 5).

Quantitative analysis of LAR+/+ nerves also demonstrated a significant increase in myelinated fiber density in sections $2 \mathrm{~mm}$ distal to the crush site compared with that found proximal to the crush point and at the crush point (Fig. 4A). This pattern of increased density of myelinated fibers distal to the crush site has been observed previously and is consistent with the process of individual regenerating axons forming multiple regenerating fibers, many of which are aborted during subsequent maturation (Murray, 1982; Jenq and Coggeshall, 1984; de Medinaceli, 1995). The failure to detect this increase in LAR-/- nerves further pointed to a loss of regenerative fiber formation in LAR-deficient mice.

The suggestion of a decreased number of regenerating fibers in LAR $-/-$ mice found in light microscopy studies was further assessed using electron microscopy. Blinded counts of electron micrographs were used to compare the density of unmyelinated axonal profiles in $\mathrm{LAR}+/+$ and $\mathrm{LAR}-/-$ nerves at the 2 and 4 $\mathrm{mm}$ sites distal to the crush lesion (Fig. 6). At the $2 \mathrm{~mm}$ point, a significant $15 \%$ decrease in unmyelinated fiber counts in LAR $-/-$ nerves was detected. At the $4 \mathrm{~mm}$ point, a highly 

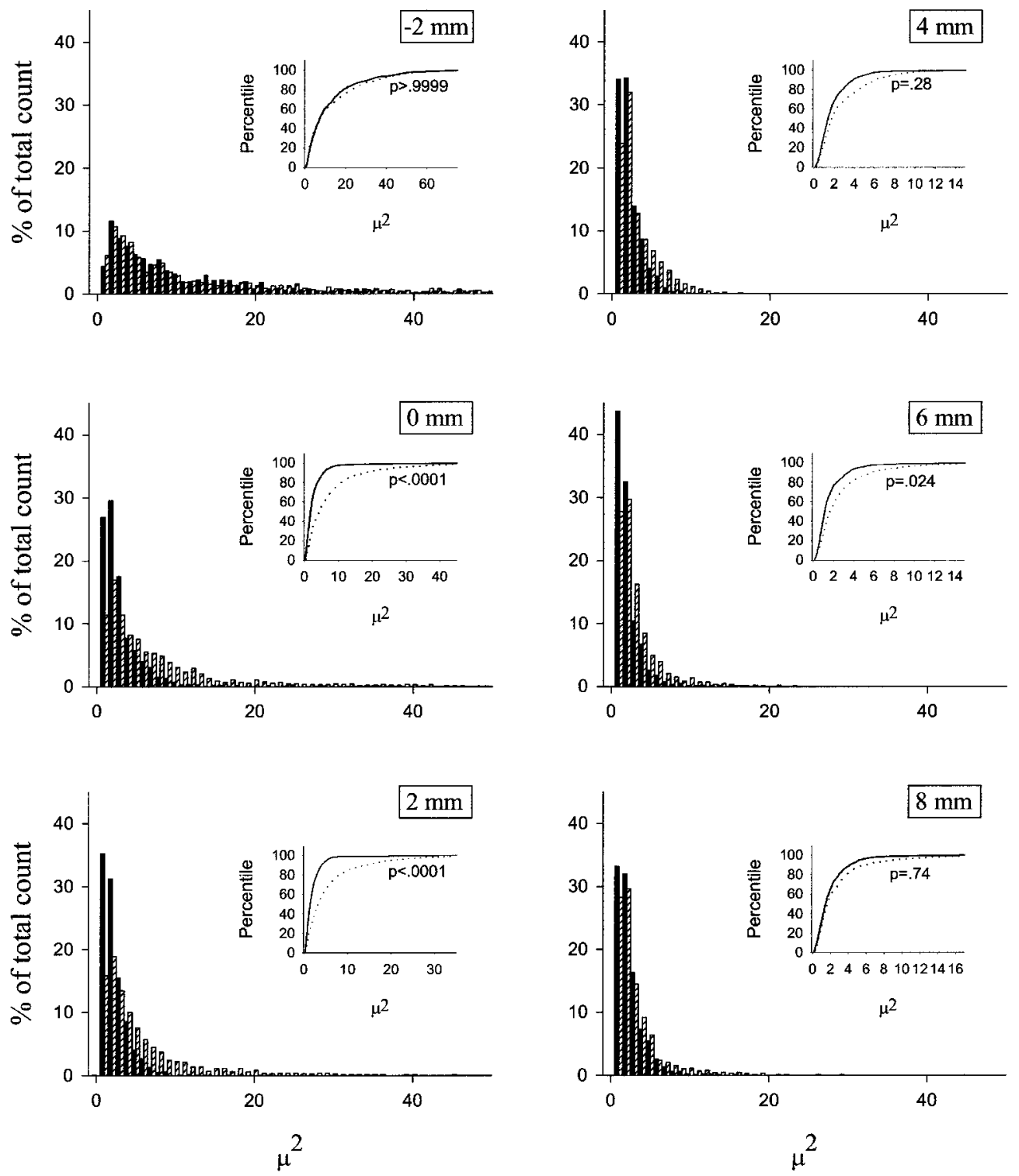

Figure 5. Histogram analysis of axonal areas. Data collected for axonal area analysis was plotted in histogram format over the indicated area ranges. Hatched bars, LAR+/+ values; black bars, LAR-/- values. For each panel, the inset shows a cumulative percentage distribution plot of axonal areas. Analysis of axonal area distributions using the Kolmogorov-Smirnov test demonstrates a highly significant loss in the proportion of larger fibers in LAR $-/$ - nerves at the crush site $(0$ $\mathrm{mm}$ ) and the $2 \mathrm{~mm}$ distal site.

significant $42 \%$ decrease in counts in LAR $-/-$ sections was found. In addition, measurements in LAR $+/+$ nerves, showed that the unmyelinated fiber density at the $4 \mathrm{~mm}$ point was $19 \%$ greater than that found at the $2 \mathrm{~mm}$ point, although this increase was not statistically significant. Increases in numbers of unmyelinated fibers at sites distal to crush injury, presumably attributable to the formation of multiple distal fibers from single proximal fibers, have been demonstrated in previous electron microscopy studies (Iannuzzelli et al., 1995).

\section{Sensory fiber regeneration is impaired in LAR-deficient transgenic mice}

LAR expression studies using in situ hybridization and immunohistological staining have shown that LAR is expressed by DRG neurons but not by motor neurons (Longo et al., 1993; Honkaniemi et al., 1998). Because LAR expression was confined primarily to DRG neurons, functional studies were focused on sensory fiber modalities. The pinch test is a well characterized function-based technique used for quantitative assessment of sensory fiber regenerative outgrowth (James et al., 1993). Application of the pinch test to $\mathrm{LAR}+/+$ and $\mathrm{LAR}-/-$ littermates derived from multiple heterozygous crosses indicated that the distal point at which functioning sensory fibers could be detected demonstrated an $\sim 3 \mathrm{~mm}$ proximal-to-distal lag in LAR $-/-$ mice compared with that measured in LAR $+/+$ mice (Fig. 7). It was of particular interest to note the complete lack of overlap in values derived from LAR+/+ and LAR-/- nerves. This lack of overlap indicated that the LAR $-/-$ associated trait of slowed sensory regeneration was fully penetrant.

\section{DISCUSSION}

Expression of LAR in DRG neurons (Longo et al., 1993; Haworth et al., 1998) and the presence of LAR protein along sciatic nerve neurites and in growth cones of regenerating cultured neurons (Zhang et al., 1998) suggested the hypotheses that LAR regulates neurite outgrowth during nerve regeneration. Because receptors modulating neurite outgrowth can either promote or inhibit outgrowth, a priori it was possible that LAR either augments or counteracts regenerative outgrowth. The persistence of LAR protein expression in DRG neurons after sciatic nerve injury suggested a role for LAR in promoting rather than inhib- 

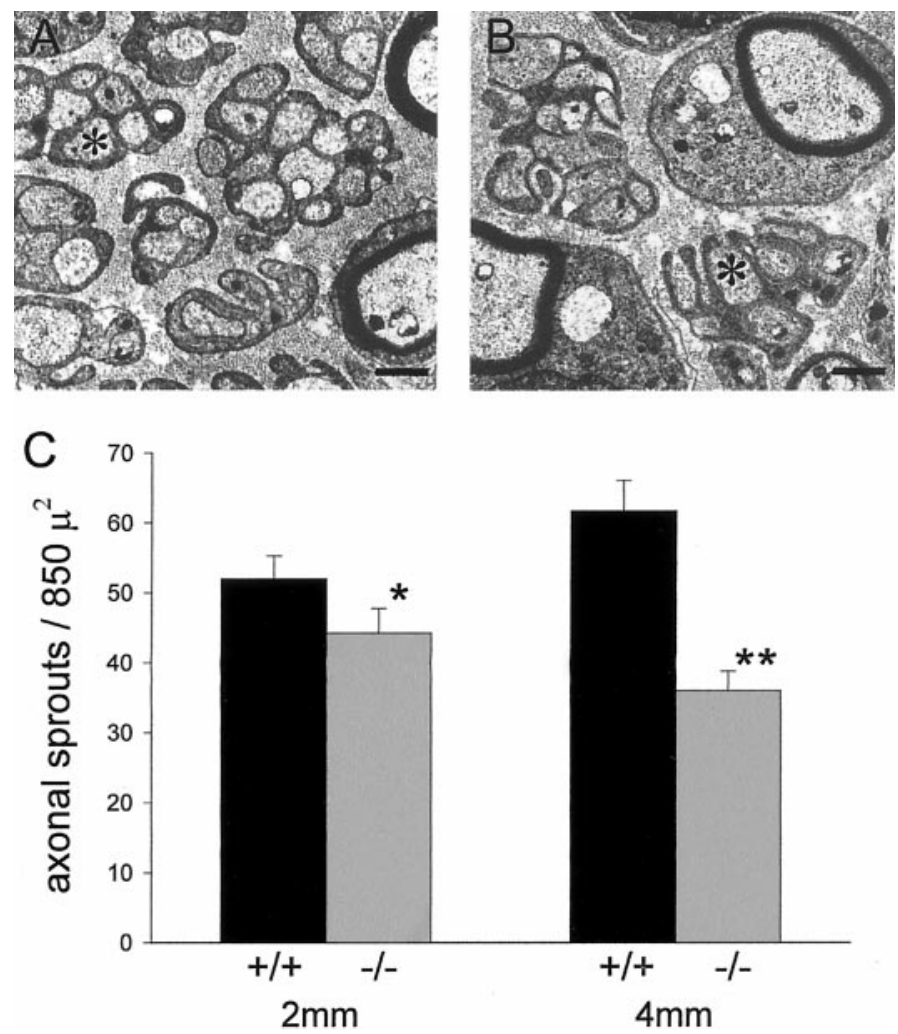

Figure 6. Electron microscopy analysis of axonal sprouting. Electron micrographs of $\mathrm{LAR}+/+(A)$ and $\mathrm{LAR}-/-(B)$ transverse nerve sections $4 \mathrm{~mm}$ distal to the crush site demonstrate typical profiles of unmyelinated fibers (indicated by the asterisks). Characteristic profiles have relatively low electron density, contain abundant microtubule profiles, and are surrounded by a relatively electron-dense axolemma (Jeng and Coggeshall, 1984; Longo et al., 1986; Gibbels, 1989). LAR - /- sections had lower numbers of unmyelinated fibers per field. $C$, Blinded counts demonstrated a significant decrease in the number of unmyelinated fibers per area in sections $2 \mathrm{~mm}\left({ }^{*} p<0.05\right)$ and $4 \mathrm{~mm}\left({ }^{* *} p<0.000001\right)$ distal to the crush site. Mann-Whitney rank sum test; mean \pm SE; $n=90$ fields counted per genotype. Scale bars, $1 \mu \mathrm{m}$.

iting neurite outgrowth. This possibility was also suggested by the observed increase in the ratio of LAR protein isoforms known to interact with laminin-nidogen complexes. More direct evidence supporting a neurite-promoting role for LAR was derived from the morphological observation of impaired sprouting and outgrowth of fibers and the functional observation of delayed outgrowth of functioning sensory fibers in LAR-deficient transgenic mice. Potential factors contributing to this lag in sensory function include decreases in proximal myelinated fiber density and size, loss of distal unmyelinated fibers, and changes in fiber conduction properties not evident on morphological studies. These findings constitute the first direct evidence supporting the hypothesis that LAR, or any PTP, is required for regenerative neurite outgrowth and function in vivo and add an important new class of proteins likely to function during mammalian neural regeneration.

The morphometric features found in the present study point to potential roles for LAR during regenerative neurite outgrowth. The increase in the density of myelinated fibers at 2 and $4 \mathrm{~mm}$ distal to the crush site in $\mathrm{LAR}+/+$ nerves is characteristic of regenerative fiber formation that occurs during the early stages of regenerative neurite outgrowth. During this process, single fibers give rise to multiple regenerating unmyelinated fibers, many of which become myelinated by the 2 week time point (Giannini et

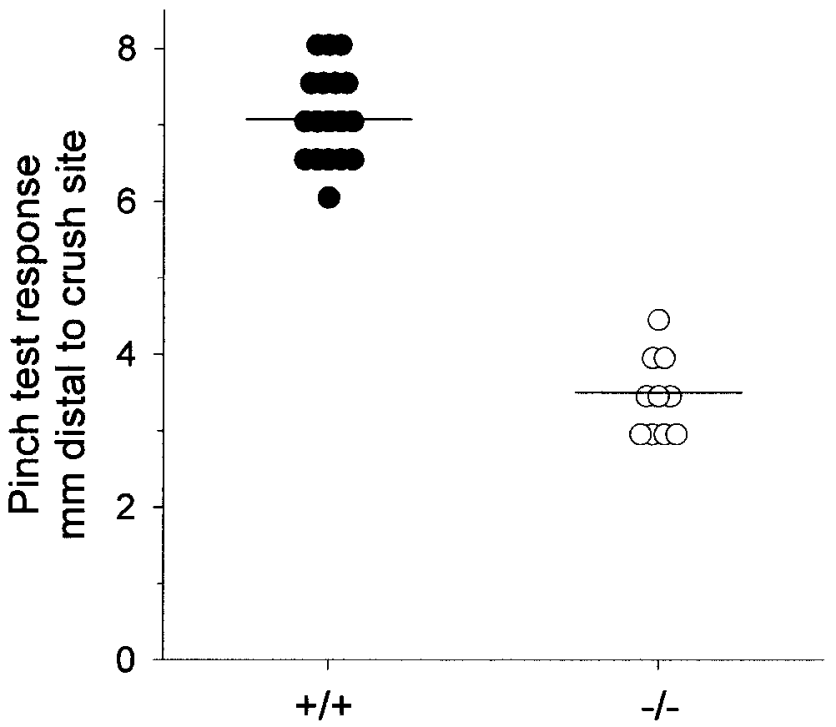

Figure 7. Functional testing of sensory fiber regeneration in normal and LAR-deficient mice. The pinch test was performed 2 weeks after nerve crush using $\mathrm{LAR}+/+$ and $\mathrm{LAR}-/$ - littermate mice in a blinded manner. Results were combined from two independent experiments using littermates derived from different heterozygous crosses. The maximum distal distances beyond the crush site at which nerve pinch responses were detected were as follows: $\mathrm{LAR}+/+, 7.08 \pm 0.14 \mathrm{~mm}(n=18$ nerves $)$; LAR $-/-, 3.50 \pm 0.17 \mathrm{~mm}(n=10$ nerves $) . p<0.0001$; two-tailed Student's $t$ test; mean \pm SE.

al., 1989; de Medinalceli, 1995; Iannuzzelli et al., 1995). Fibers failing to elongate along adequate distal tracts degenerate while others persist. The decrease in the density of myelinated fibers in LAR $-/-$ nerves at the 2 and $4 \mathrm{~mm}$ points raises the possibility that LAR contributes to the formation of regenerating fibers and/or their subsequent elongation. Alternatively, it is possible that formation and elongation of unmyelinated fibers occurs equally in $\mathrm{LAR}+/+$ and $\mathrm{LAR}-/-$ nerves but that myelination fails in LAR $-/-$ nerves. This latter scenario is made less likely by the finding of consistently increased myelin to axon area ratios in regenerating fibers in $\mathrm{LAR}-/-$ nerves. This increase in myelin to axon area ratio suggests a primary axonal deficiency rather than a primary failure of myelination. Confirmation of an impairment in fiber outgrowth in LAR $-/-$ mice was obtained using quantitative electron microscopy, which demonstrated significantly decreased counts of regenerating unmyelinated fibers in distal sections.

The present morphological findings in LAR-deficient mice of decreased axonal caliber and delayed neurite outgrowth support current models of LAR molecular mechanisms. As discussed above, insect and mammalian studies suggest that LAR regulates activities and phosphorylation states of $\beta$-catenin, Abl, Trio, Mena, and possibly other important proteins regulating actin and peripherin cytoskeletal dynamics relevant to neurite outgrowth. Given the loss of axonal areas in LAR-/- nerves, it is of interest to note that one major factor controlling axonal caliber is the content, organization, and phosphorylation state of neurofilament proteins (Hoffman and Griffin, 1993). The present findings will encourage quantitative assessment of activation and phosphorylation states of LAR downstream targets in LAR-deficient models.

The significant decrease in the proportion of LAR protein isoforms containing the LASE-c insert in the fifth FN III domain 
of LAR points to additional mechanisms by which LAR might modulate sprouting and neurite outgrowth. Studies of recombinant LAR proteins with or without the LASE-c insert demonstrate that isoforms not containing LASE-c bind to lamininnidogen complexes, whereas isoforms containing LASE-c do not bind (O'Grady et al., 1998). It is of particular interest to note that laminin is present in the extracellular matrix surrounding regenerating fibers (Longo et al., 1984) and has a well established role in promoting sensory fiber neurite outgrowth (Fawcett and Keynes, 1990; Griffin and Hoffman, 1993). These observations suggest the possibility that injury-induced downregulation of the proportion of LAR isoforms containing LASE-c might upregulate LAR interaction with extracellular laminin-nidogen complexes and thereby contribute to regenerative fiber formation and/or outgrowth. In future studies, it will be important to determine the identity of ligands present in regenerating peripheral nerve that interact with the LAR ectodomain to regulate neurite outgrowth.

The absence of an abnormal phenotype in uninjured adult sciatic nerves in LAR $-/-$ mice indicates that either LAR does not play a major role during developmental neurite outgrowth or, alternatively, that abnormalities present during development caused by LAR deficiency are resolved via compensatory mechanisms. The latter scenario was suggested in studies of PTP $\sigma$ deficient mice in which Wallace et al. (1999) noted a decrease in the size myelinated fibers in sciatic nerve examined at $21 \mathrm{~d}$ of age that was no longer detectable in the 6 month age group. Whether regenerative neurite outgrowth in adult $\mathrm{PTP} \sigma$ mice is impaired remains to be investigated. The determination of whether LAR regulates neurite outgrowth during peripheral nerve development will require studies at multiple developmental time points. The absence of markedly abnormal phenotypes in various PTPdeficient, adult noninjury models has led to the conclusion that many PTPs share "redundant" functions. The major contrast found in the present study between the relative lack of a detectable phenotype in uninjured LAR $-/-$ nerves and the marked alterations in regenerative and functional phenotype in LAR - / - nerves after injury raises a note of caution in application of the term redundant. Clearly, redundancy in a developmental context does not necessarily predict redundancy in other contexts.

Two standard caveats apply to most current transgenic mouse knock-out models. First, the site of the transgene in the targeted gene often allows a small N-terminal or other protein fragment to be expressed. The presence of a protein fragment encoded by the targeted gene raises the potential of a "dominant negative" rather than a deficiency-based mechanism of altered phenotype. The absence of a detectable abnormal phenotype in uninjured nerves in LAR - / - mice makes this mechanism unlikely; however, a dominant negative effect can never be ruled out entirely. A second important factor to consider is the possibility that the abnormal regenerative phenotype observed in the present LAR $-/-$ mice resulted from a unique strain mixture that was somehow maintained in all LAR $-/$ - littermate mice despite multiple heterozygous crosses. The combination of using of mice having undergone at least six DBA backcrosses (estimated congenic homogeneity of $>95 \%$ ) (Silver, 1995), examining littermate controls, and finding a fully penetrant regenerative phenotype in multiple litters (Fig. 7) make this mechanism highly unlikely. These alternative, non-LAR deficiency explanations for the results found in the present study will also be addressed by assessing nerve regeneration in additional transgenic models of LAR deficiency. Schaapveld et al. (1997) created an LAR-deficient mouse in a C57BL/6 strain background via the insertion of a transgene into the LAR intracellular phosphatase domain. Preliminary studies of these mice demonstrate impaired sensory sciatic nerve regeneration after nerve crush (van Lieshout et al., 1999). The finding of impaired regeneration in a second LARdeficient model created in a distinct strain background and derived via a distinct gene disruption strategy indicates that the impairment in regeneration found in the present study is likely to be a result of LAR deficiency per se rather than a result of the alternative mechanisms proposed above.

The present studies will encourage the production of inducible LAR-deficient transgenic mice to further assess LAR function in vivo. The finding of impaired neurite outgrowth during the early phases of postcrush regeneration will also encourage long-term studies to determine whether LAR contributes to long-range neurite outgrowth, synapse formation, and functional recovery of sensory function. These findings will also encourage the examination of other models of neural plasticity in LAR-deficient and other PTP-deficient mice.

\section{REFERENCES}

Auer RN (1994) Automated nerve fiber size and myelin sheath measurement using microcomputer-based digital image analysis: theory, method, and results. J Neurosci Methods 51:229-238.

Baker MW, Macagno ER (2000) The role of a LAR-like receptor tyrosine phosphatase in growth cone collapse and mutual-avoidance by sibling processes. J Neurobiol 44:194-203.

Baker MW, Rauth SJ, Macagno ER (2000) Possible role of the receptor protein tyrosine phosphatase HmLAR2 in interbranch repulsion in a leech embryonic cell. J Neurobiol 45:47-60.

Bashaw GJ, Kidd T, Murray D, Pawson T, Goodman CS (2000) Repulsive axon guidance: Abelson and Enabled play opposing roles downstream of the Roundabout receptor. Cell 101:703-715.

Bateman J, Shu H, Van Vactor D (2000) The guanine nucleotide exchange factor trio mediates axonal development in the Drosophila embryo. Neuron 26:93-106.

Bixby JL (2000) Receptor tyrosine phosphatases in axon growth and guidance. NeuroReport 11:R5-R10.

Chisholm A, Tessier-Lavigne M (1999) Conservation and divergence of axon guidance mechanisms. Curr Opin Neurobiol 9:603-615.

Debant A, Serra-Pages C, Seipel K, O’Brien S, Tang M, Park SH, Streuli M (1996) The multidomain protein Trio binds the LAR transmembrane tyrosine phosphatase, contains a protein kinase domain, and has separate rac-specific and rho-specific guanine nucleotide exchange factor domains. Proc Natl Acad Sci USA 93:5466-5471.

de Medinaceli L (1995) Interpreting nerve morphometry data after experimental traumatic lesions. J Neurosci Methods 58:29-37.

den Hertog J (1999) Protein-tyrosine phosphatases in development. Mech Dev 85:3-14.

Desai CJ, Sun Q, Zinn K (1997) Tyrosine phosphorylation and axon guidance: of mice and flies. Curr Opin Neurobiol 7:70-74.

Elchebly M, Wagner J, Kennedy TE, Lanctor C, Michaliszyn E, Itie A, Drouin J, Tremblay ML (1999) Neuroendocrine dysplasia in mice lacking protein tyrosine phosphatase $\sigma$. Nat Genet 21:330-333.

Fawcett JW, Keynes RJ (1990) Peripheral nerve regeneration. Annu Rev Neurosci 13:43-60.

Frykman GK, McMillan PJ, Yegge S (1988) A review of experimental methods measuring peripheral nerve regeneration in animals. Orthop Clin North Am 19:209-219.

Gershon TR, Baker MW, Nitabach M, Macagno ER (1998) The leech receptor protein tyrosine phosphatase HmLAR2 is concentrated in growth cones and is involved in process outgrowth. Development 125:1183-1190.

Giannini C, Lais AC, Dyck PJ (1989) Number, size, and class of peripheral nerve fibers regenerating after crush, multiple crush, and graft. Brain Res 500:131-138.

Gibbels R (1989) Morphometry of unmyelinated nerve fibers. Clin Neuropathol 8:179-187.

Griffin JW, Hoffman PH (1993) Degeneration and regeneration in the peripheral nervous system. In: Peripheral neuropathy, Ed 3 (Dyck PJ, Thomas PK, Griffin JW, Low PA, Poduslo JP, eds), pp 361-376. Philadelphia: Saunders.

Haworth K, Shu KK, Stokes A, Morris R, Stoker A (1998) The expression of receptor tyrosine phosphatases is responsive to sciatic nerve crush. Mol Cell Neurosci 12:93-104.

Hoffman PN, Griffin JW (1993) The control of axonal caliber. In: Pe- 
ripheral neuropathy, Ed 3 (Dyck PJ, Thomas PK, Griffin JW, Low PA, Poduslo JP, eds), pp 361-376. Philadelphia: Saunders.

Honkaniemi J, Z hang JS, Yang T, Longo FM (1998) Alternative splicing of the LAR LASE-a insert is coordinated with regional and intraneuronal distribution of LAR. Mol Brain Res 60:1-12.

Iannuzzelli PG, Murray M, Murphy EH (1995) Regenerative axonal sprouting in the cat trochlear nerve. J Comp Neurol 354:229-240.

James MK, Nils D, Bjorn H, Martin K, Goran L (1993) The influence of predegeneration on regeneration through peripheral nerve grafts in the rat. Exp Neurol 122:28-36.

Jenq C-B, Coggeshall RE (1984) Effects of sciatic nerve regeneration on axonal populations in tributary nerves. Brain Res 295:91-100.

Kanaan S, Saade NE, Haddad JJ, Abdelnoor AM, Atweh SF, Jabbur SJ, Safieh-Garabedian B (1996) Endotoxin-induced local inflammation and hyperalgesia in rats and mice: a new model for inflammatory pain. Pain 66:373-379.

Krueger NX, Van Vactor D, Wan HI, Gelbart WM, Goodman CS, Saito $\mathrm{H}$ (1996) The transmembrane tyrosine phosphatase DLAR controls motor axon guidance in Drosophila. Cell 84:611-622.

Lanier LM, Gertler FB (2000) From Abl to actin:Abl tyrosine kinase and associated proteins in growth cone motility. Curr Opin Neurobiol 10:80-87.

Lanier LM, Gates MA, Witke W, Menzies AS, Wehman AM, Macklis JD, Kwiatkowski D, Soriano P, Gertler FB (1999) Mena is required for neurulation and commissure formation. Neuron 22:313-325.

Ledig MM, Haj F, Bixby JL, Stoker AW, Mueller BK (1999) The receptor tyrosine phosphatase $\mathrm{CRYP} \alpha$ promotes intraretinal axon growth. J Cell Biol 147:375-388.

Liebl EC, Forsthoefel DJ, Franco LS, Sample SH, Hess JE, Cowger JA, Chandler MP, Shupert AM, Seeger MA (2000) Dosage-sensitive, reciprocal genetic interactions between the Abl tyrosine kinase and the putative GEF trio reveal trio's role in axon pathfinding. Neuron 26:107-118.

Lin MZ, Greenberg ME (2000) Orchestral maneuvers in the axon: Trio and the control of axon guidance. Cell 101:239-242.

Longo FM, Hayman E, Davis G, Manthorpe M, Engvall E, Ruoslahti E, Varon S (1984) Neurite promoting factors and extracellular matrix components accumulating in vivo within nerve regeneration chambers. Brain Res 309:105-117.

Longo FM, Powell HC, LeBeau J, Gerrero MR, Heckman H, Myers RR (1986) Delayed nerve regeneration in streptozotocin diabetic rats. Muscle Nerve 9:385-393.

Longo FM, Martignetti JA, Le Beau JM, Zhang JS, Barnes JP, Brosius J (1993) Leukocyte common antigen-related receptor-linked tyrosine phosphatase. Regulation of mRNA expression. J Biol Chem 268:26503-26511.

Murray M (1982) A quantitative study of regenerative sprouting by optic axons in goldfish. J Comp Neurol 209:352-362.

O'Grady P, Thai TC, Saito H (1998) The laminin-nidogen complex is a ligand for a specific splice isoform of the transmembrane protein tyrosine phosphatase LAR. J Cell Biol 141:1675-1684.

Rath EM, Kelly D, Boldin TW, Popko B (1995) Impaired peripheral nerve regeneration in a mutant strain of mice (Enr) with a Schwann cell deficit. J Neurosci 15:7226-7237.

Schaapveld RQJ, Schepens JTG, Robinson GW, Attema J, Oerlemans FTJJ, Fransen JAM, Streuli M, Wieringa B, Hennighausen L, Hendriks WJAJ (1997) Impaired mammary gland development and function in mice lacking LAR receptor-like tyrosine phosphatase activity. Dev Biol 188:134-146.
Schaapveld RQJ, Schepens JTG, Bachner D, Attema J, Wieringa B, Jap PHK, Hendriks WJAJ (1998) Developmental expression of the cell adhesion molecule-like protein tyrosine phosphatases LAR, RPTP $\delta$ and RPTP $\sigma$ in the mouse. Mech Dev 77:59-62.

Silver LM (1995) Mouse genetics, pp 46-49. Oxford: Oxford UP.

Skarnes WC, Moss JE, Hurtley SM, Beddington RS (1995) Capturing genes encoding membrane and secreted proteins important for mouse development. Proc Natl Acad Sci USA 92:6592-6596.

Stoker AW, Dutta R (1998) Protein tyrosine phosphatases and neural development. BioEssays 20:463-472.

Sun Q, Bahri S, Schmid A, Chia W, Zinn K (2000) Receptor tyrosine phosphatases regulate axon guidance across the midline of the Drosophila embryo. Development 127:801-812.

Uetani N, Kato K, Ogura H, Mizuno K, Kawano K, Mikoshiba K, Yakura H, Asano M, Iwakura Y (2000) Impaired learning with enhanced hippocampal long-term potentiation in PTPd-deficient mice. EMBO J 19:2775-2785.

van Lieshout EMM, van der Heijden I, Hendriks WJAJ, Van Der Zee CEEM (1999) LAR protein tyrosine phosphatase deficient mice show impaired peripheral sensory and motor nerve regeneration following crush lesion. Soc Neurosci Abstr 25:88.4.

van Lieshout EMM, Van Der Heijden I, Hendriks WJ, Van Der Zee CE (2001) A decrease in size and number of basal forebrain cholinergic neurons is paralleled by diminished hippocampal cholinergic innervation in mice lacking leukocyte common antigen-related protein tyrosine phosphatase activity. Neuroscience 102:833-841.

Van Vactor D (1998) Protein tyrosine phosphatases in the developing nervous system. Curr Opin Cell Biol 10:174-181.

Wallace MJ, Batt J, Fladd CA, Henderson JT, Skarnes W, Rotin D (1999) Neuronal defects and posterior pituitary hypoplasia in mice lacking the receptor tyrosine phosphatase PTPs. Nat Genet 21:334-338.

Wang J, Bixby JL (1999) Receptor tyrosine phosphatase- $\delta$ is a homophilic neurite-promoting cell adhesion molecule for CNS neurons. Mol Cell Neurosci 14:370-384.

Wills Z, Marr L, Zinn K, Goodman CS, Van Vactor D (1999a) Profilin and the $\mathrm{Abl}$ tyrosine kinase are required for motor axon outgrowth in the Drosophila embryo. Neuron 22:291-299.

Wills Z, Bateman J, Korey CA, Comer A, Van Vactor D (1999b) The tyrosine kinase $\mathrm{Abl}$ and its substrate enabled collaborate with the receptor phosphatase Dlar to control motor axon guidance. Neuron 22:301-312.

Yang T, Martignetti JA, Massa SM, Longo FM (2000) LAR tyrosine phosphatase receptor: altered expression of mRNA and protein in the NEDH rat line exhibiting spontaneous pheochromocytoma. Carcinogenesis 21:125-131.

Yeo TT, Yang T, Massa SM, Zhang JS, Honkaniemi J, Butcher LL, Longo FM (1997) Deficient LAR expression decreases basal forebrain cholinergic neuronal size and hippocampal cholinergic innervation. J Neurosci Res 47:348-360.

Zhang JS, Longo FM (1995) LAR tyrosine phosphatase receptor: alternative splicing is preferential to the nervous system, coordinated with cell growth and generates novel isoforms containing extensive CAG repeats. J Cell Biol 128:415-431.

Zhang JS, Honkaniemi J, Yang T, Longo FM (1998) LAR tyrosine phosphatase receptor: a developmental isoform is present in neurites and growth cones and its expression is regional- and cell-specific. Mol Cell Neurosci 10:271-286. 